\title{
Evaluation of Podological Risk at Type 2 Diabetics Tracked at the Mark Sankale Diabetes Center in Dakar
}

\author{
Michel Assane Ndour ${ }^{*}$, Demba Diedhiou1, Djiby Sow ${ }^{1}$, Ibrahima Mane Diallo1, Aissatou Diallo ${ }^{1}$, \\ Ahmed Limane Barrage ${ }^{1}$, Ibrahima Kindy Diallo', Muriel Diembou' ${ }^{1}$, Lala Bouna Seck ${ }^{2}$, \\ Pape Adama Dieng', Maimouna Ndour Mbaye1, Anna Sarr ${ }^{1}$
}

${ }^{1}$ Department of Internal Medicine, Abass Ndao Hospital Center, Dakar, Senegal

${ }^{2}$ Department of Neurology, Fann University Hospital Center, Dakar, Senegal

${ }^{3}$ Department of Cardiovascular Thoracic Surgery, Fann University Hospital Center, Dakar, Senegal

Email: *michelassanendour@yahoo.fr

How to cite this paper: Ndour, M.A., Diedhiou, D., Sow, D., Diallo, I.M., Diallo, A., Barrage, A.L., Diallo, I.K., Diembou, M., Seck, L.B., Dieng, P.A., Mbaye, M.N. and Sarr, A. (2020) Evaluation of Podological Risk at Type 2 Diabetics Tracked at the Mark Sankale Diabetes Center in Dakar. Journal of Diabetes Mellitus, 10, 41-50.

https://doi.org/10.4236/jdm.2020.102004

Received: March 5, 2020

Accepted: May 4, 2020

Published: May 7, 2020

Copyright $\odot 2020$ by author(s) and Scientific Research Publishing Inc. This work is licensed under the Creative Commons Attribution International License (CC BY 4.0).

http://creativecommons.org/licenses/by/4.0/

\begin{abstract}
Introduction: The diabetic foot is a real public health problem due to its economic and functional impact with a high risk of amputations. The objective was to determine the podiatric risk of type 2 diabetics according to the classification of the International Working Group on the Diabetic Foot (IWGDF) in order to put in place suitable prevention measures. Patients and Methods: This was a cross-sectional, descriptive and analytical study conducted over 12 months from May 01, 2018 to May 01, 2019 and concerning subjects with type 2 diabetes regularly followed up at the Marc Sankale Center at Abass Ndao Hospital in Dakar. Results: Two hundred (200) patients were collected with an average age of $58.9 \pm 10$ years, a sex ratio of 0.43 . The majority of our patients had diabetes less than 5 years of age (52\%) and were on non-insulin medication (63\%). The average HbAlc level was $8.1 \%$. Besides diabetes, high blood pressure and dyslipidemia were the most common cardiovascular risk factors in $65 \%$ and $25 \%$, respectively. The main podiatric risk factors were: neuropathy (75.5\%), arteriopathy (31.5\%), deformities (19.5\%), history of ulceration (24\%) and amputation (2\%). Factors associated with the risk of ulceration were: walking barefoot (42\%), wearing tight shoes (26.5\%), wearing unsuitable socks (46\%), gait disturbance (39\%), traumatic pedicure (3.5\%). The podiatric risk assessment according to the IWGDF grading had identified a podiatric risk foot in $80 \%$ of the cases. Depending on the grade of injury, it was a grade $0(20 \%)$, grade $1(32 \%)$, grade $2(34 \%)$ and grade 3 (14\%) risky foot. A significant correlation was established between the onset of diabetic foot and age $(p<0.05)$, HbAlc $(p<0.02)$, the duration of diabetes $(p<0.01)$. Conclusion: Podiatric assessment remains an essential point in
\end{abstract}


the fight against complications of diabetes. This study demonstrates the high risk of developing diabetic foot, hence the importance of good grade planning to reduce the impact.

\section{Keywords}

Diabetic Foot, Podiatric Risk, Prevention, Marc Sankale Center

\section{Introduction}

The diabetic foot constitutes a world scourge in perpetual increase. Contributing factors to its occurrence, such as neuropathy and arteritis, are present in more than $10 \%$ in the diagnosis of type 2 diabetes [1]. The annual incidence of foot ulceration is $1 \%-4 \%$ and its prevalence is $4 \%-10 \%$. This suggests that the lifetime risk can range from $15 \%$ to $25 \%$ [2] [3]. Ignorance, poor care and lack of resources are situations with risk of frightening complications such as osteitis, gangrene or later amputation [4]. About $80 \%$ of non-traumatic amputations of the lower limbs were performed in diabetic subjects [5] and more than $85 \%$ of them were precipitated by an ulcer [6].

The Marc Sankale Diabetes Center in Dakar is an international benchmark in the management of diabetes mellitus. Foot lesions, account for $2 \%$, are responsible for $28 \%$ of amputations and $15 \%$ of mortality [7]. An annual evaluation covering 37,173 treatment procedures, Diallo et al. [8] reported a limb injury in 93.9\%, dominated by an ulcer (46.7\%), hence the need to register in prevention. The podiatric risk assessment is an accessible tool for preventing injuries and amputation of the foot in diabetic subjects. Its application in diabetic subjects could prevent $50 \%$ of amputations [7]. Since 2002, the gradation of podiatric risk has been adopted by the diabetic foot monitoring committee. It is based on the international classification developed by the International Working Group of the Diabetic Foot (IWGDF) [9]. Given the magnitude of the scourge, we therefore undertook this study with the objective of assessing the podiatric risk in diabetic subjects followed at the Marc Sankale Center. The aim was to propose adequate prevention measures.

\section{Methodology}

It was a cross-sectional, descriptive, analytical study, conducted from May 01, 2018 to May 01, 2019 at the Marc Sankale Center at Abass Ndao Hospital. Any type 2 diabetic patients, regardless of gender, age, ethnicity, or religion were included. They were received at the control consultation and regularly followed up. The patients received a full clinical examination, in addition to the assessment of glycemic balance and other cardiovascular risk factors. Patients who met the inclusion criteria were reviewed to complete the explorations. It was a complement to the neurological examination with the use of the monofilament, the biothesiometer and the realization of the Systolic Pressure Index (SPI). The pa- 
tient was informed of the subject of our study and his consent sought for inclusion. He was also made aware of his diabetes status and the complications he would be exposed to. The data were collected on a pre-established individual questionnaire which was addressed to the objectives of the study, in strict compliance with medical confidentiality. Non-consent, reduced mobility, the existence of another cause of neuropathy was criteria for non-inclusion in the study. For the purposes of the study, the parameters studied were:

- socio-demographic data (age, sex);

- the profile of diabetes mellitus (seniority, ongoing treatment, balance on the basis of fasting blood sugar and glycated hemoglobin, chronic complications), cardiovascular risk factors associated with diabetes (hypertension, dyslipidemia, obesity, sedentary lifestyle, tobacco);

- the main podiatric risk factors: neuropathy, arteriopathy, deformity, history of amputation and ulceration of the foot;

- the associated podiatric risk factors: wearing unsuitable socks, wearing overly tight shoes, barefoot walking, gait disturbances, traumatic pedicure.

At the end of the data recording, a gradation of the risk of foot ulceration was carried out according to the model proposed by the IWGDF [8].

To determine the size of the sample, this formula: $n=(z) 2 p(1-p) d 2 . n=$ sample size;

$Z=$ confidence level according to the normal centered reduced law (for a confidence level of 95\%, $z=1.96$, for a confidence level of 99\%, $z=2.575$ ); $p=$ estimated proportion of the population with the characteristic (when unknown, $p=$ 0.5 ); $d=$ tolerated margin of error (for example, the actual proportion is to be $5 \%)$. The sample size that were calculated from the formula in our study equal 210.

Data entry and analysis was carried out using an electronic database developed with IBM SPSS 24.0 software. For the descriptive part, the data were presented as a percentage for the qualitative variables and as means (with standard deviation) for the quantitative variables. The bivariate analysis was done using Chi-square tests (Pearson and Yates) for the comparison of proportions. The difference was considered statistically significant for a $p<0.05$. Variables with more than $10 \%$ missing data were not analyzed.

\section{Results}

A total of 200 questionnaires out of 210 were usable. The patients consisted of 61 men and 139 women, a sex ratio of 0.43 . The mean age of the patients was $58.9 \pm$ 10 years. The average age of diabetes was $6.4 \pm 4$ years. The average blood sugar was $1.6 \pm 0.7 \mathrm{~g} / \mathrm{l}$ and the glycated hemoglobin $(\mathrm{HbAlc}$ ) was $8.1 \% \pm 2.6 \%$. Cardiovascular risk factors associated with diabetes were dominated by high blood pressure (44\%), dyslipidemia (25\%). Menopause was present in 105 women (75.5\% of women). The epidemiological, clinical and paraclinical profile of our patients is summarized in Table 1. 
Table 1. Epidemiological, clinical and paraclinical profile of our patients.

\begin{tabular}{|c|c|}
\hline Data & Frequency (\%) \\
\hline Effective & $200(100 \%)$ \\
\hline Women & $139(69.5 \%)$ \\
\hline Average age & $58.9 \pm 10$ years \\
\hline \multicolumn{2}{|l|}{ Age of diabetes } \\
\hline $0-5$ years & $104(52 \%)$ \\
\hline $6-10$ years & $36(18 \%)$ \\
\hline Over 10 years & $60(30 \%)$ \\
\hline Non-insulin diabetic drugs & $126(63 \%)$ \\
\hline Insulin diabetic drugs & $58(29 \%)$ \\
\hline Diet only & $16(8 \%)$ \\
\hline Blood sugar $>1.26 \mathrm{~g} / \mathrm{l}$ & $160(80 \%)$ \\
\hline $\mathrm{HbAlc}>7 \%$ & $104(52.2 \%)$ \\
\hline High blood pressure (hypertension) & $88(44 \%)$ \\
\hline Obesity & $25(12.5 \%)$ \\
\hline Dyslipidemia & $50(25 \%)$ \\
\hline Sedentary lifestyle & $28(14 \%)$ \\
\hline
\end{tabular}

Clinical neurological exploration with the Semmes-Weinstein monofilament found hypoaesthesia in 120 patients (60\%), 23 cases (11.5\%) of anesthesia and 07 cases $(3.5 \%)$ of hyperesthesia. On a biothesiometer, sensory neuropathy was found in 159 cases (79.5\%) including 20 patients aged under 50 and in 139 patients aged over 50 .

The posterior pedal and tibial pulse were not seen in 31 patients $(15.5 \%)$. The systolic pressure index (PSI) was less than 0.9 in 53 patients $(26.5 \%)$ and more than 1.3 in 10 patients (5\%). Of the 63 patients (31.5\%) with clinical arterial disease, 25 were able to have a lower limb Doppler ultrasound. It confirmed obliterating arterial disease of the lower limbs in all patients. The other foot lesions were dominated by inter-toe intertrigos (5\%), followed by cracks (3\%) and hyperkeratosis (2\%). The deformations were found in $19.5 \%$ of the cases. These were claw toes (10\%), hallux valgus (5\%), gale (4.5\%) (see Figure 1 and Figure 2).

Among the main podiatric risk factors, neuropathy was the most represented with $75.5 \%$, followed by arteriopathy (31.5\%) and a history of ulceration $(24 \%)$ (see Table 2). In bi-varied analysis, a statistically significant link was established between neuropathy and $\mathrm{HbAlc}(p=0.02)$. The same was true for arterial disease and factors such as age $(p=0.04)$, age of diabetes $(p=0.04)$, and dyslipidemia $(p=0.07)$. The deformities were associated with age $(p=0.01)$. Both ulceration and amputation history were associated with diabetes imbalance $(p=0.04, p$ $=0.05$ respectively). 


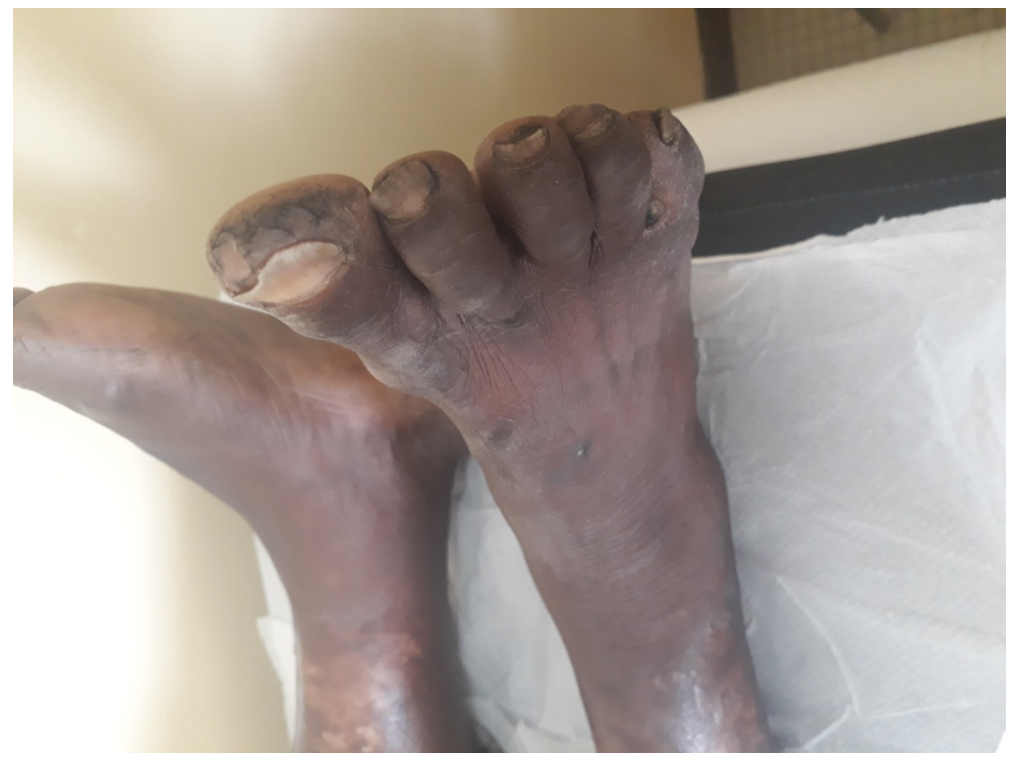

Figure 1. Cracks and hyperkeratosis of the toes.

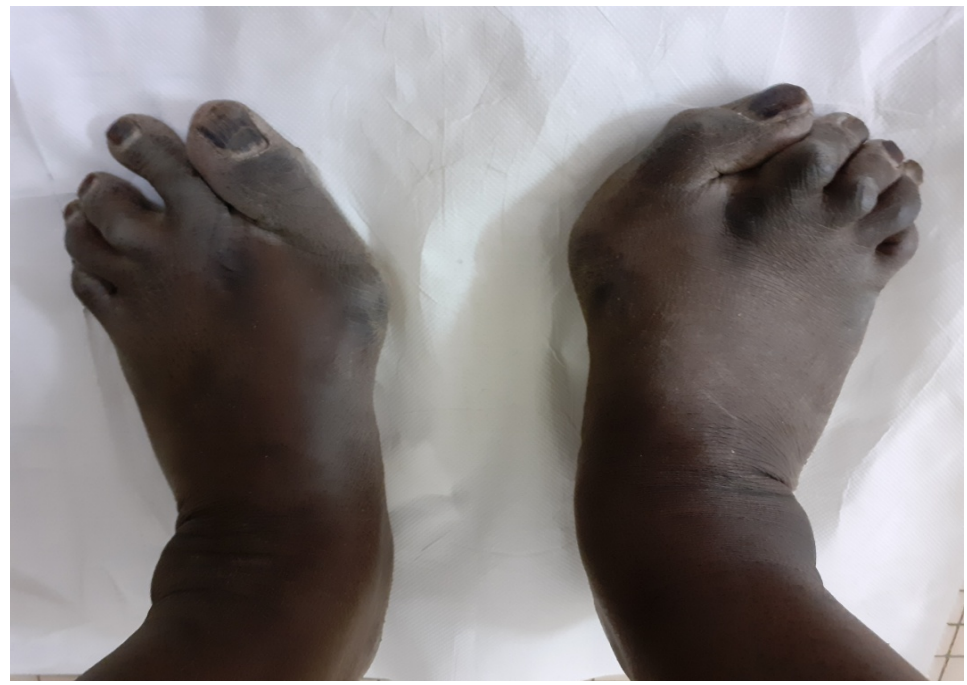

Figure 2. Claw toes, Hallux valgus.

Table 2. Frequency of the main podiatric risk factors according to the IWGDF.

\begin{tabular}{ccc}
\hline Podiatric risk factors & Number of patients & Percentages \\
\hline Neuropathy & 151 & $75.5 \%$ \\
Arteriopathy & 63 & $31.5 \%$ \\
Deformities & 39 & $19.5 \%$ \\
History of ulceration & 48 & $24 \%$ \\
History of amputation & 4 & $2 \%$ \\
\hline
\end{tabular}

The distribution of patients by grade according to the IWGDF classification [8] is summarized in Table 3. Grades 1 and 2 were predominant in $32 \%$ and $34 \%$ respectively. Women had a higher podiatric risk $(p=0.03)$. Grade 1 was 
predominant in patients whose diabetes had progressed for less than 5 years $(p=$ 0.01 ), while grade 2 was predominant in patients with diabetes aged 5 years or more $(p=0.001)$. Patients with an HbAlc level $>7 \%$ were the most represented in grade $3(p=0.02)$. Table 4 summarizes the correlation of the grade of podiatric risk according to gender, $\mathrm{HbAlc}$ and the duration of diabetes.

The factors associated with the risk of ulceration were: wearing unsuitable socks (46\%), walking barefoot (42\%), gait disturbance (39\%), wearing tight shoes (26.5\%), traumatic pedicure (3.5\%). Among the associated podiatric risk factors, walking barefoot, wearing unsuitable socks and wearing sandals were the most frequently associated with a high podiatric risk.

Table 3. Distribution of patients by podiatric grade.

\begin{tabular}{ccc}
\hline Podiatric risk & Number of patients & Percentages \\
\hline $\begin{array}{c}\text { Grade 0 } \\
\text { (Without sensory neuropathy) } \\
\text { Grade 1 } \\
\text { (Isolated neuropathy) } \\
\text { Grade 2 } \\
\text { arteriopathy or deformities) } \\
\text { Grade 3 }\end{array}$ & 40 & $20 \%$ \\
$\begin{array}{c}\text { (Neuropathy + } \\
\text { History of ulceration (grade 3a) and/or } \\
\text { amputation (grade 3b) } \\
\text { Total }\end{array}$ & 68 & $32 \%$ \\
\hline
\end{tabular}

Table 4. Correlation of podiatric risk according to gender, HbAlc and the duration of diabetes.

\begin{tabular}{cccc}
\hline Grade of podiatric risk & \multicolumn{2}{c}{ Correlation settings } & p value \\
\hline By gender & Woman & Man & \\
Grade 0 & 29 & 11 & 0.6 \\
Grade 1 & 42 & 22 & 0.4 \\
Grade 2 & 23 & 15 & 0.06 \\
Grade 3 & 15 & 13 & 0.04 \\
According to the age of the diabetes & $<5$ years & $\geq 5$ years & \\
Grade 0 & 25 & 15 & 0.13 \\
Grade 1 & 41 & 23 & 0.01 \\
Grade 2 & 21 & 47 & 0.00 \\
Grade 3 & 17 & 11 & 0.3 \\
According to HbAlc & $\leq 7 \%$ & $>7 \%$ & \\
Grade 0 & 27 & 13 & 0.005 \\
Grade 1 & 29 & 35 & 0.6 \\
Grade 2 & 36 & 32 & 0.8 \\
Grade 3 & 8 & 20 & 0.02 \\
\hline
\end{tabular}




\section{Discussion}

We conducted this study on the evaluation of podiatric risk in type 2 diabetic patients over a 12-month period at the Marc Sankale diabetes center in Dakar. It presented limits because the vascular explorations were incomplete. Since patient care is expensive, especially financial difficulties were faced by patients in performing the most common exams.

The predominance of women is known in most African series [10] [11] [12]. It could be explained by a greater sedentary lifestyle, a risk factor for obesity and therefore the onset of type 2 diabetes. However, our study, like that of Leye A. et al. [13] did not find a significant correlation between gender and podiatric risk. The average age of our patients was comparable to the literature [9] [13] and very close to the period of onset of type 2 diabetes [14]. The age-related podiatric risk, found in our series, could be explained by the duration of progression of diabetes. Half of our patients had diabetes which progressed between 0 and 5 years or $52 \%$. This can be explained by the fact that the Marc Sankale center, the national reference in diabetology, is the focal point for most new cases of diabetes. It is after the implementation of a first care plan that patients are redirected to decentralized care structures via a counter referral system. Despite a shorter history of diabetes ( 0 to 5 years), the complications were not negligible, confirming the progressive and silent nature of diabetes. Our data on the risk of developing arteritis according to the age of diabetes are already known from the literature [15]. Among the cardiovascular risk factors found, hypertension was the most represented (65\%) followed by dyslipidemia (25\%). The association of type 2 diabetes and cardiovascular risk factors is well established [14]. Their impact on the occurrence of arterial disease via atheroma plaque also remains widely reported. This would explain the high prevalence of arterial disease in our elderly patients at high cardiovascular risk.

With regard to podiatric risk factors, peripheral neuropathy was the most common with $75.5 \%$. This result is higher than that of Traoré et al. [12] in Mali, Mbaye N.M et al. [16] and Diallo et al. [8] in Senegal. These authors reported frequencies of $55.6 \%$ and $13.3 \%, 72.3 \%$ respectively. This neuropathy is predominant among the risk factors for foot ulceration [6] and increased with the poor glycemic balance $(p=0.02)$ [2].

The frequency of arterial disease in our series was higher than the $15.5 \%$, $21.6 \%, 12.8 \%$ respectively reported by Traoré et al. [12] in Mali, Raharinavalona et al. [17] in Madagascar and Hamonet et al. [18] in France. Our results can be explained by the systematization of SPI in the research of arteriopathy. The correlation of arterial disease with dyslipidemia and age is thought to be due to loss of vascular elasticity and atherosclerosis. These two parameters also evolve with the age of diabetes [15]. Foot deformities were present in $19.5 \%$ of cases. This result is similar to the $20 \%$ reported by Raharinavalona et al. [17]. Age was the only factor influencing the occurrence of deformity in our study $(p=0.01)$. According to the literature, elderly diabetic patients are particularly affected by 
complications of the foot. In fact, older subjects probably have a longer course of development of diabetes, so would be more at risk of developing complications linked to diabetes [19]. Deformities of the foot accentuate the areas of hyperpressure and conflict in poorly fitted diabetic patients. This is being at the origin of the occurrence of ulceration or even amputation [17]. The history of foot ulceration was $24 \%$ in this study. There was a statistically significant link between the glycemic imbalance and a history of foot ulceration $(p=0.04)$. Four patients (2\%) had already had a lower limb amputation. This result is lower than in the African series where the amputation rate hovers around $46.3 \%$ to $50 \%$ [20]. This low rate is explained by the fact that our evaluation was more targeted at patients in routine consultation.

Prevention of diabetic foot by screening for podiatric risk remains important. Hence the interest in gradation according to the IWGDF which allowed us to identify a foot at risk in 160 out of 200 patients, or $80 \%$. Leye A. et al. [13] reported a rate of $58.7 \%$. Grade 1 (isolated neuropathy) was present in $32 \%$ of our patients. This result is higher than that of Leye A. et al. serie [13] which found $9.8 \%$. There was a statistically significant link between grade 1 and the duration of diabetes $(p=0.01)$. The frequency of grade 2 (Neuropathy and Arteriopathy or deformity) at $34 \%$ was comparable to data from the series of Raharinavalona et al. [17]. As for grade 3 (history of ulceration and/or amputation) at 14\%, its frequency seems intermediate compared to the $17.3 \%$ reported by Leye A. et al. [13]. Grade 3 increased with dyslipidemia $(p=0.02)$. This high risk could be explained by the fact that the majority of our patients had unbalanced diabetes, which was sometimes overlooked for a long time. It is reported in the literature that the poor balance of diabetes increases the podiatric risk. Among the factors associated with podiatric risk, walking barefoot and wearing tight shoes were the most frequent with $46 \%$ each. These results are superior to those of Raharinavalona et al. [17] who found that $35 \%$ of their patients walked barefoot and $30 \%$ wore tight shoes. This result could be explained by the lack of awareness of the risk and the precarious socio-economic conditions in which our populations live. The latter would increase the risk.

\section{Conclusion}

The assessment of podiatric risk according to the gradation of the International Working Group on the Diabetic Foot (IWGDF) allowed us to identify the foot at risk in $80 \%$. There is a statistically significant link between the gradation of podiatric risk, the age of diabetes, poor glycemic control and dyslipidemia, hence the need for systematic, early and annual evaluation in order to avoid late diagnosis. Associated with this is the strengthening of the education of diabetic patients in order to slow down the onset of complications, identify and early prevent feet at risk according to grade.

\section{Conflicts of Interest}

The authors declare no conflicts of interest regarding the publication of this paper. 


\section{References}

[1] UK Prospective Diabetes Study (UKPDS) Group (1998) Intensive Blood-Glucose Control with Sulphonylureas or Insulin Compared with Conventional Treatment and Risk of Complications in Patients with Type 2 Diabetes (UKPDS 33). The Lancet, 352, 837-853. https://doi.org/10.1016/S0140-6736(98)07019-6

[2] Bartus, C.L. and Margolis, D.J. (2004) Reducing the Incidence of Foot Ulceration and Amputation in Diabetes. Current Diabetes Reports, 4, 413-418.

https://doi.org/10.1007/s11892-004-0049-x

[3] Boulton, A.J., Vileikyte, L., Ragnarson-Tennvall, G., et al. (2005) The Global Burden of Diabetic Foot Disease. The Lancet, 366, 1719-1724. https://doi.org/10.1016/S0140-6736(05)67698-2

[4] Mayfield, J.A., Reiber, G.E., Sanders, L.J., Janisse, D. and Pogach, L.M. (1998) Preventive Foot Care in People with Diabetes. Diabetes Care, 21, 2161-2177. https://doi.org/10.2337/diacare.21.12.2161

[5] Reiber, G.E., Lipsky, B.A. and Gibbons, G.W. (1998) The Burden of Diabetic Foot Ulcers. The American Journal of Surgery, 176, 5S-10S. https://doi.org/10.1016/S0002-9610(98)00181-0

[6] Trautner, C., Haastert, B., Giani, G., et al. (1996) Incidence of Lower Limb Amputations and Diabetes. Diabetes Care, 19, 1006-1009. https://doi.org/10.2337/diacare.19.9.1006

[7] Camara, A.Y. (2003) Les problems de la prise en charge du pied diabetique. Exemple du centre Marc Sankalé; Th Med Universite Cheikh Anta DIOP (Senegal). N043.

[8] Diallo, I.M., Diédhiou, D., Sow, D., Ndour, M.A., Barrage, A.L., Ka-Cissé, M., et al. (2019) Profil clinique et évolutif des lésions de la peau et des parties molles chez les diabétiques en 2017 à la salle de pansement du Centre Marc Sankalé de Dakar. Pan African Medical Journal, 32, 209. https://doi.org/10.11604/pamj.2019.32.209.18524

[9] Schaper, N.C. (2004) Diabetic Foot Ulcer Classification System for Research Purposes: A Progress Report on Criteria for Including Patients in Research Studies. Diabetes/Metabolism Research and Reviews, 20, 90-95. https://doi.org/10.1002/dmrr.464

[10] Pataky, Z. and Vischer, U. (2007) Diabetic Foot Disease in the Elderly. Diabetes \& Metabolism, 33, S56-S65. https://doi.org/10.1016/S1262-3636(07)80057-7

[11] Leye, A., Ndiaye, N., Diack, N.D., Ndour, M.A., et al. (2017) Screening of Peripheral Artery Disease by Systematic Measurement of Ankle-Brachial Index among Diabetic Patients in Dakar. Journal of Diabetes Mellitus, 7, 321-329. https://doi.org/10.4236/jdm.2017.74027

[12] Traore, D., Sylla Sow, D., Konaté, M., Sidibé, O., Mariko, M., Sy, D., et al. (2019) Screening of Foot at Risk in Diabetic Patients. Open Journal of Internal Medicine, 9 , 62-71. https://doi.org/10.4236/ojim.2019.93009

[13] Leye, A., Diack, N.D., Leye, Y.M., et al. (2019) Assessment of the Podiatric Risk on Diabetics in Dakar Hospital Area: Cross-Sectional Study in Regard to 142 Patients. Journal of Diabetes Mellitus, 8, 1-8. https://doi.org/10.4236/jdm.2018.81001

[14] Passa, Ph. (1998) Risque cardio-vasculaire et diabète. Annales d endocrinologie, 59, 329-333.

[15] Diedhiou, D., Sarr, A., Lèye, M.M.M., et al. (2012) Foot Ulcer in Diabetes Mellitus: Epidemiological, Clinical, Etiological and Evolutional Aspects in Abass Ndao Hospital Center. Dakar Medical, 57, 154-161.

[16] Mbaye, N.M., Sarr, A., Diop, S.N., et al. (2008) Descriptive Study of Diabetic Foot at 
the Marc Sankale Diabetes Center. Dakar Medical, 53, 205-212.

[17] Raharinavalona, S.A., Ramalanjaona, H.R., Andrianera, N., Patrick Rakotomalala, A.D. and Ramahandridona, G. (2017) Dépistage du risque podologique chez les diabétiques de type 2 à Antananarivo. Pan African Medical Journal, 27, 213.

https://doi.org/10.11604/pamj.2017.27.213.11311

[18] Hamonet, J., Verdié-Kessler, C., Daviet, J.-C., Denes, E., Nguyen-Hoang, C.-L., Salle, J.-Y., et al. (2010) Evaluation of a Multidisciplinary Consultation of Diabetic Foot. Annals of Physical and Rehabilitation Medicine, 53, 306-318. https://doi.org/10.1016/j.rehab.2010.04.001

[19] Sano, D., Tieno, H., Drabo, Y. and Sanou, A. (1999) Prise en charge du pied diabétique: A propos de 42 cas au CHU de Ouagadougou. Médecine d Afrique Noire, 46, 307-311.

[20] Sidibé, O. (2015) Dépistage du pied à risque chez les diabétiques dans le service de médecine et d'endocrinologie de l'hôpital du Mali [Thèse de médecine]. [Mali] 